\title{
What is so special about the sharing economy: The customer experience view
}

\author{
David Havir ${ }^{1, *}$ \\ ${ }^{1}$ Brno University of Technology, Faculty of Business and Management, Department of Management, \\ Kolejní 2906/4, 61200 Brno, Czech Republic
}

\begin{abstract}
Research background: From time to time utilization of modern technology innovatively disrupts the industry, as is true for sharing economy companies such as Airbnb and Uber. These companies achieved global success with their platform-enabled businesses connecting the demand of individuals with underutilized resources of others. Besides the competitive prices enabled by controversial practices, they are widely criticized for, these companies attracted masses of customers, not only the price-sensitive ones. Relating to that, the recent marketing phenomenon of customer experience is aiming to help companies systematically understand the perception and resulting actions of customers, and to better manage their marketing mix to gain competitive advantage and increase overall performance.

Purpose of the article: The purpose of this article is to explore the nature of customer experience in the area of sharing economy to better understand the importance of experiential factors the marketing metrics of sharing economy companies are driven by.

Methods: The research is based on the pilot data collection through online and offline surveys and the subsequent partial least square structural equation modeling (PLS-SEM) analysis of the data from 86 respondents.

Findings \& Value added: This paper provides insight into the area of sharing economy through the identification of the factors of needs fulfillment level (particularly social) and effective resource management during the customer experience as the ones with the positive effect (medium and weak-medium) on the memorized customer experience quality, while the human perception engagement is surprisingly found as the weak contributor. The memorized customer experience quality was found to have a medium positive effect on customer satisfaction which further has the medium-strong positive effect on the positive word-of-mouth and customer loyalty of customers of the sharing economy companies.
\end{abstract}

Keywords: customer experience; sharing economy; uber; airbnb; PLSSEM

JEL Classification: $M 31 ; P 32 ; D 91$

\footnotetext{
* Corresponding author: david.havir@,vutbr.cz
} 


\section{Introduction}

Customer experience management is one of the key marketing topics of the recent millennium. Academics as well as managers are trying to understand the concept of customer experience as its management is considered as one of the main approaches for differentiation, competitive advantage, and increased financial performance [1]. In the last decade, the market was, on the other hand, disrupted by the companies providing platforms for sharing economy services, such as Airbnb and Uber. These companies, by the smart utilization of new technologies, innovated customer experience mainly in fields of accommodation and transportation.

This article explores customer experience created by the union of platforms provided by sharing economy companies and the service providers, identifies key contributors to the recollected customer experience quality, and its effect on key marketing metrics. The next sections of this chapter briefly present the marketing concept of customer experience and the phenomenon of sharing economy, hypotheses are formulated in its end. The next chapter is dedicated to the research methodology. Chapter Results and Discussion present key results of the analysis and presents the evaluation of the hypothesis. The final chapter Conclusions presents key findings as well as limitations of the research and possible avenues for future research..

\subsection{Customer Experience}

Customer experience can be broadly defined as ,non-deliberate, spontaneous responses and reactions to offering-related stimuli embedded within a specific context" [2]. While this definition can be considered the most accurate thanks to its non-reductive nature, De Keyser et al. [1] criticize it with a statement that such a broad definition does not practically help and decomposition of customer experience is needed to make it manageable.

De Keyser et al. [1] decompose customer experience to CX components/building blocks: interaction touchpoints, the context of experience, qualities of experience. Klaus \& Maklan [3] recognize four dimensions of customer experience quality: product experience, outcome focus, moments-of-truth, peace-of-mind. Schmitt [4] proposed five „strategical experiential modules": sense, feel, think, act, relate. An enormous number of researchers come with their own models and components, dimensions, and antecedents of customer experience [5]. Many of the models built upon the cognition-affect-behavior model, some use the stimulusorganism-response framework [6], some consciousness-emotion-value model [7] or attribute-consequence-value means-end chain [8], and some tries to combine more approaches into one. Some authors approach customer experience through the evaluation of stimuli characteristics, some through the evaluation of the dimensions of the perceptive process, some authors perceive customer experience mainly as hedonistic, the fragmentation is enormous.

From the works of Becker \& Jaakkola [2] and De Keyser et al. [1] it could be, once again, concluded that customer experience is a very complex multidisciplinary concept that includes everything and its comprehension is a condition by the connection of many topics from many different fields and therefore should not be reduced, because such a reduction might lead us back not forward in the marketing knowledge. From this point of view, this work builds upon theory [8] built upon the knowledge from the fields of marketing, psychology, philosophy, human-computer interaction, and quality of life that suggests to combine hedonic and utilitarian aspects of a company's offering with its economic impact on customer's resources and views customer experience as the cumulative memorized psychological result of all perceived stimuli during the loosely bounded time frame connected by the customer to his interactions with the brand hired to help him with some task. The theory then assumes that 
the quality of such a memorized customer experience influences overall customer satisfaction with a brand and further influences his loyalty and positive word-of-mouth [8].

\subsection{Sharing Economy}

Sharing economy or collaborative economy [9] can be, according to Schlagwein et al. [11, p. 18] defined as ,peer-to-peer IT-facilitated peer-to-peer model for commercial or noncommercial sharing of underutilized goods and service capacity through an intermediary without a transfer of ownership". In other words, the sharing economy companies act as intermediaries that provide the platforms through which providers of the underutilized goods or services can meet with the potential customers seeking such good or service. The most known two companies operating under the term ,sharing economy" are Airbnb, the platform primarily for utilization of the underutilized accommodation, and Uber, the platform primarily for the utilization of the underutilized transportation vehicles and time of their drivers. [12] These companies have achieved considerable success from the years of their foundation $(2008,2009)$, but have also received considerable criticism [12], in any case, they revolutionized the fields where they operate and innovated the overall customer experience that allowed them to reach a substantial number of customers, especially the younger ones [13].

This paper, therefore, aims at the identification of the key factors that have a positive effect on the recollected customer experience quality with the sharing economy companies. Research further explores the role of recollected customer experience quality in relation to customer's loyalty to and positive word-of-mouth for sharing economy companies.

\subsection{Research hypothesis}

Based on the customer experience theory [8] introduced above, a conceptual model with hypothesized relationships between concepts was developed and hypotheses were formulated as follows.

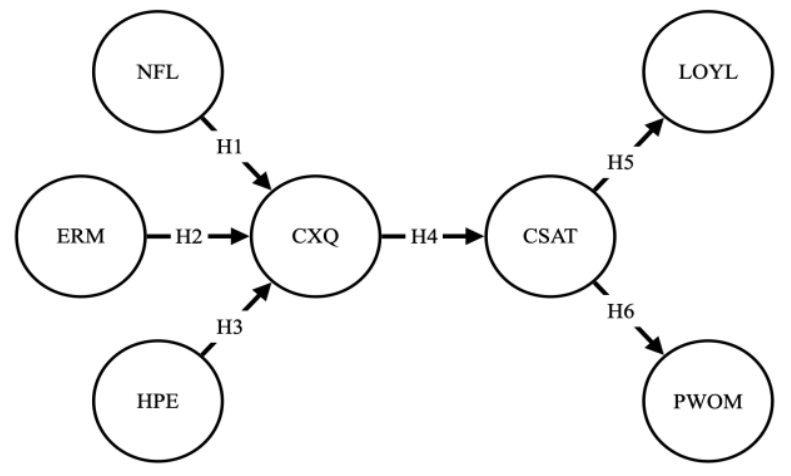

Fig. 1. Conceptual model based on [8]

In the context of the sharing economy experience:

H1: Recollected needs fulfillment level (NFL) has a positive effect on the recollected customer experience quality (CXQ).

H2: Recollected efficient resource management (ERM) has a positive effect on the recollected customer experience quality (CXQ). 
H3: Recollected human perception engagement (HPE) has a positive effect on the recollected customer experience quality (CXQ).

H4: Recollected customer experience quality (CXQ) has a positive effect on customer satisfaction (CSAT).

H5: Customer satisfaction (CSAT) has a positive effect on customer loyalty (LOYL).

H6: Customer satisfaction (CSAT) has a positive effect on positive word of mouth (PWOM).

\section{Methods}

This paper uses an online and offline questionnaire with closed questions based on the Likert scale to collect the opinions on customer experience, attitudes, and tendencies of sharing economy services customers. Collected quantitative data were cleaned through the process of statistical and visual identification and further exclusion of responses containing suspicious response patterns. The resulting set of cleaned data was analyzed with the partial least square structural equation modeling (PLS-SEM) method. The methodology of this paper follows recommendations of Hair et al. [14, 15] and Sarstedt et al. [16] for applying PLS in structural equation modeling.

\subsection{Target population and sample}

The respondents for this research were purposefully selected from the students of Czech university predominantly belonging to the so-called category ,generation $Z$ “. The rest of the respondents were reached through the questionnaire distributed online and purposefully placed to the thematically relevant places on social media with the expectation to acquire data from ,generation $\mathrm{Z}$ “ and youngest ,generation $\mathrm{Y}^{\prime}$ members from the Czech Republic. The selection of age groups reflects Denning's [17] view of the sharing economy as appealing to young generations.

\subsection{Data collection}

The data for this research were collected through the online and offline surveys with closed questions based on the 7-point Likert scale ranging from „Strongly disagree“ to „Strongly agree“. Questions asked were related to the concepts of the conceptual model, therefore customer satisfaction, customer loyalty, word-of-mouth, customer experience quality, needs fulfillment, resource demand, and perception (for relevant questions see Table 1 in Appendix). The questions asked were selected from the pool of items extracted from the customer experience research papers (see Havir, 2019, for the identical methodology) and linked to the concepts of the conceptual model for maintaining richness but while eliminating redundancy. For the concept with no related items in the pool, new items were designed and the whole questionnaire was prepared for the pretest through this research. [18]

Customer satisfaction (CSAT) was measured by the Czech equivalent of the following statements: 1) „I am satisfied with my experience with Uber / Bolt / Airbnb.“, 2) „Overall, I am satisfied with Uber / Bolt / Airbnb." Customer loyalty (LOYL) was measured by statements: 1) „Even if it were more difficult to use Uber / Bolt / Airbnb, I would still use it.“, 2) „At the next similar occasion I will primarily choose Uber / Bolt / Airbnb.“, 3) „For all future similar occasions I will use only Uber / Bolt / Airbnb.“, 4) „I’m loyal to Uber / Bolt / Airbnb." Positive word-of-mouth (PWOM) was measured by statements: 1) "Based on my experience I will recommend(ed) Uber / Bolt / Airbnb to a colleague or friend.“, 2) „If someone would like to advise on a similar situation, I would recommend him Uber / Bolt / Airbnb.“, 3) „Based on my experience, I will encourage(d) someone around to try Uber / Bolt 
/ Airbnb.“ Customer experience quality (CXQ) was measured by the statement: „I rate this experience as great."

Basic human needs (BSC) part of needs fulfillment level (NFL) higher-order construct was measured by statements: 1) „I had a feeling of assurance.“, 2) „I had a feeling of security.“; social human needs (SOC) part by statements: 1) „I had a feeling that I was being treated friendly.“, 2) „I had a feeling that I'm a member of a community.“, 3) "I had a feeling I was treated fairly and with respect."; human needs for growth (GRW) part by statements: 1) „I had the feeling that I was enriched.“, 2) „I had the feeling that it was contributing to my self-realization.“, 3) „I had the feeling that it was contributing to my development.“, 4) „I had the feeling that I could do something good."; utilitarian customer needs (UT) part with statements: 1) „Everything was fully functional.“, 2) „Everything was of good quality.“, 3) „I felt that everything was fulfilling its purpose.“, 4) „My intended intention to use the service was fully met."; and hedonic customer needs (HED) part of needs fulfillment level (NFL) higher-order construct was measured by statements: 1) „I had a feeling of luxury.“, 2) „I had a feeling of real enjoyment/pleasure.“, 3) „My expectations were exceeded.“, 4) „My best imagination was exceeded.“, 5) „I was absorbed or experienced the feeling of flow.“, 6) „I experienced a sense of escape from everyday reality.“

Management of energy resources (ENR) part of efficient resource management (ERM) higher-order construct was measured by statements: 1) „I was physically or mentally unburdened.“, 2) „My energy (physical, mental) was not required much.“, 3) „I had the feeling that my physical and mental energy was well invested.“, 4) „I felt like I was physically or mentally rested by the experience."; money resources (MNY) part was measured by statements: 1) „I felt that everything was commensurate with the cost of the service.“, 2) „I felt that my finances were well invested.“; and time resources (TIM) part was measured by statements: 1) „I felt that everything was helping to save my time.“, 2) „I felt that everything was time-efficient.“, 3) „I felt that everything was helping me spend my time well.“

Sensory (SNS) part of the human perception engagement (HPE) higher-order construct was measured by the following statements: 1) ,I felt that everything contributed to the delight of my senses (appearance, design, smell, temperature, purity).“, 2) „I had a feeling of comfort.“, 3) „I felt a pleasant atmosphere.“; cognitive (COG) part was measured by statements: 1) „I learned something new.“, 2) „I engaged my creativity.“, 3) „I satisfied my curiosity.“, 4) „I was inspired.“; affective (AFF) part was then measured by statements: 1) „I was made happy.“, 2) „I was positively surprised.“, 3) „I was amused.“, 4) „I was pleased.“, 5) „I experienced a feeling of excitement/enthusiasm.“; and behavioral (BEH) part of human perception engagement (HPE) higher-order construct was measured by: 1) „I had the opportunity to get actively involved.“, 2) „My future behavior was positively influenced.“, 3) „My lifestyle was positively influenced.“

\subsection{Data cleaning}

Collected data were statistically analyzed, the strings of answers were visualized based on the quantitative value of the answer. The questionnaire was divided into the thematic parts and these parts further into thematic sub-parts, for each such part and sub-part the standard deviation was computed as well as the overall score reflecting variation between respondent's answers. Answer sets with suspicious total filling time and suspicious patterns of answers were inspected in the detail and in the case of straight-lining excluded from the final set.

\subsection{Data analysis}

Cleaned data were then analyzed with partial least square structural equation modeling (PLSSEM) method in SmartPLS 3.2.8 software. Structural equation modeling (SEM) is a 
statistical method for estimating and testing causal relationships between variables and has recently two main types, PLS-SEM which is a primarily exploratory second-generation technique of multivariate analysis, and CB-SEM which is primarily confirmatory [14]. Based on the criteria for selecting the right type, PLS-SEM was selected for its advantages in pilot studies, the exploratory nature of research, and the intention to test the theoretical framework. The process of analysis and reporting followed the instructions by Hair et al. $[14,15]$ and Sarstedt et al. [16]. Since the proposed conceptual model is a higher-order model the analysis will be carried out in two stages $[14,16]$. In the first stage, measurement model assessment will be conducted, while in the second stage, measurement, as well as structural model assessment, will be conducted, both in accordance with Hair et al. [14, 15].

\section{Results and Discussion}

In this part of the paper, the results of the PLS-SEM analysis are reported according to Hair et al. $[14,15]$, the discussion of the results follows.

\subsection{Respondent profile}

For this pilot study, 104 sets of answers were collected while 19 of them were discarded by the cleaning process. From the resulting 85 sets of answers, 59 respondents $(69,4 \%)$ built their answers upon the experience with the accommodation sharing economy service (Airbnb) and 26 respondents (30,6\%) upon the experience with the transportation sharing economy service (Uber, Bolt). Sixty respondents were between $18-24$ years old $(70,6 \%)$, and 25 respondents between 25-34 years old $(29,4 \%)$. Forty-nine respondents were women $(57,7 \%)$ and thirty-six respondents were men $(42,3 \%)$. The highest level of education of 54 respondents $(64,3 \%)$ was a bachelor's degree, for 16 respondents $(19 \%)$ a high-school degree, for 12 respondents $(14,3 \%)$ a master's degree, for 1 respondent $(1 \%)$ it is a higher vocational degree and for 1 respondent (1\%) a doctor's degree. Eighty percent of the respondents were students.

\subsection{First stage - Measurement model assessment}

In the first stage, outer loadings, internal consistency reliability (rho A), convergent validity (AVE), and discriminant validity (cross-loadings, Fornell-Larcker criterion, HTMT) for the lower-order components were assessed for the reflective measurement models and compared with the recommended values (Hair et al., 2019). All the indicators with loadings above 0,708 were retained as well as following indicators with lower loadings - HPE_AFF3 $(0,617)$, HPE_AFF5 $(0,665)$, LOYL4 $(0,696)$, NFL_SOC3 $(0,681)$, PWOM3 $(0,702)$ as their exclusion did not improve internal consistency reliability. In terms of construct validity, all values of Cronbach's Alpha, rho A, and Composite Reliability were higher than 0,7 . The average variance extracted (AVE), the metric for convergent validity, was also in all cases above the threshold of 0,5 . In terms of discriminant validity, no cross-loading issues were found, and all AVE2 were larger than the correlation between constructs in the relevant row and column (Fornell-Larcker Criterion). In the case of the heterotrait-monotrait (HTMT) metric, most of the values were lower than the recommended threshold of 0,85 ; for the remaining few - NFL_SOC x NFL_UT $(0,897)$, HPE_COG x HPE_BEH $(0,868)$ - threshold 0,9 was adopted because of the similarity of constructs. All HTMT confidence intervals did not include 1 but NFL_SOC $\rightarrow$ NFL_UT $(0,999)$ and HPE_COG $\rightarrow$ HPE_BEH $(0,952)$ upper bounds were close to 1 (Bootstrapping based on 5000 subsamples). 
Convergent validity, collinearity (VIF), the statistical significance of weights, and relevancy of indicators were then assessed for the formative measurement model and also compared with the recommended values. [15] As there was a no reflectively measured indicator for ERM_MNY, convergent validity could not be assessed. In terms of the collinearity, no condition index value was above 30 and no variance inflation factor (VIF) value was equal or above 3 . The assessment of the significance of weights revealed that all p-values are less 0,05 and confidence intervals did not include 0 (Bootstrapping based on 5000 subsamples), while the weight of ERM_MNY1 is 0,664 and of ERM_MNY2 is 0,434. All loadings were higher than 0,5 .

\subsection{Results from the second stage - Measurement model assessment}

In the second stage, the same criteria as in stage one were applied for the reflective and formative measurement models assessment.

Table 1. Assessment of the reflective measurement models ( $2^{\text {nd }}$ stage $)$

\begin{tabular}{|c|c|c|c|}
\hline Outer loadings & Loading & $p 0,708$ & $\begin{array}{l}\text { All indicators with loadings above } 0,708 \text { retained; exclusion } \\
\text { of indicators NFL_GRW }(0,562) \text { and NFL_HED }(0,674) \\
\text { would improve internal consistency reliability, but they were } \\
\text { retained to not compromise content validity. }\end{array}$ \\
\hline \multirow[t]{3}{*}{$\begin{array}{l}\text { Construct } \\
\text { reliability }\end{array}$} & $\begin{array}{l}\text { Cronbach's } \\
\text { Alpha }\end{array}$ & \multirow[t]{3}{*}{$\geq 0,7$} & All values above the threshold. \\
\hline & Rho A & & All values above the threshold. \\
\hline & $\begin{array}{l}\text { Composite } \\
\text { Reliability }\end{array}$ & & All values above the threshold. \\
\hline \begin{tabular}{|l|} 
Convergent \\
validity
\end{tabular} & AVE & $\geq 0,5$ & All values above the threshold. \\
\hline \multirow[t]{4}{*}{$\begin{array}{l}\text { Discriminant } \\
\text { validity }\end{array}$} & $\begin{array}{l}\text { Cross } \\
\text { Loadings }\end{array}$ & & No cross-loading issues. \\
\hline & \begin{tabular}{|l|} 
Fornell- \\
Larcker \\
Criterion
\end{tabular} & & $\begin{array}{l}\text { AVE2 of NFL not larger than the correlation between NFL } \\
\text { and NFL might indicate an issue. }\end{array}$ \\
\hline & HTMT & $<0,85$ & $\begin{array}{l}\text { All HTMT was lower than } 0,85 \text {. As HTMT is considered } \\
\text { superior to Fornell-Larcker Criterion, no issue is found. }\end{array}$ \\
\hline & $\begin{array}{l}\text { HTMT } \\
\text { confidence } \\
\text { interval }\end{array}$ & $\begin{array}{l}\text { not } \\
\text { include } 1\end{array}$ & No interval includes 1. \\
\hline
\end{tabular}

Notes: Bootstrapping based on 5000 subsamples

Table 2. Assessment of formative measurement models ( $2^{\text {nd }}$ stage $)$

\begin{tabular}{|l|l|l|l|}
\hline $\begin{array}{l}\text { Convergent } \\
\text { validity }\end{array}$ & & $\begin{array}{l}\text { No reflectively measured indicators of the } \\
\text { ERM and HPE. }\end{array}$ \\
\hline Collinearity & Condition Index & $<30$ & No Condition Index value above 30. \\
\cline { 2 - 4 } & Variance Proportions & $>0,9 /<0,5$ & \\
\cline { 2 - 4 } & VIF & $<3$ & All VIF value equal or above 3. \\
\hline & P-value & $<0,05$ & \\
\hline
\end{tabular}




\begin{tabular}{|c|c|c|c|}
\hline $\begin{array}{l}\text { Significance } \\
\text { of weights }\end{array}$ & $95 \%$ confidence interval & not include 0 & $\begin{array}{l}\text { P-values less than }<0,05 \text { and confidence } \\
\text { interval does not include } 0 \text { for ERM_MNY, } \\
\text { ERM_TIM, HPE_AFF, HPE_SNS, but p- } \\
\text { values of ERM_ENR }(0,458), \text { HPE_COG } \\
(0,151) \text { and HPE_BEH }(0,190) \text { are above } \\
0,05 \text { and confidence intervals include } 0 . \\
\text { Weights are: ERM_ENR }(0,017), \\
\text { ERM_MNY }(0,433), \text { ERM_TIM }(0,628), \\
\text { HPE_SNS }(0,407), \text { HPE_COG }(-0,217), \\
\text { HPE_AFF }(0,671), \text { HPE_BEH }(0,212) .\end{array}$ \\
\hline $\begin{array}{l}\text { Relevance of } \\
\text { indicators }\end{array}$ & Loading & $\geq 0,5$ & $\begin{array}{l}\text { All loadings higher than } 0,5 \text { except } \\
\text { HPE_COG }(0,492) \text {, all loadings are } \\
\text { statistically significant. }\end{array}$ \\
\hline
\end{tabular}

Notes: Bootstrapping based on 5000 subsamples

\subsection{Results from the second stage - Structural model assessment}

The structural model was then assessed using collinearity (VIF), coefficient of determination (R2 values), predictive relevance (Q2 values), PLS Predict, and statistical significance and relevance of path coefficients [15].

Table 3. Assessment of structural model ( $2^{\text {nd }}$ stage)

\begin{tabular}{|c|c|c|c|}
\hline Collinearity & VIF & $<3$ & All VIF values are equal to or above 3. \\
\hline $\begin{array}{l}\text { Coefficient of } \\
\text { determination }\end{array}$ & $\mathrm{R}^{2}$ value & $\begin{array}{l}<0,9 \\
(0,25 ; 0,5 \\
0,75)\end{array}$ & $\begin{array}{l}\text { CSAT - 0,334 (0,326 adj. }) \text { - weak-moderate } \\
\text { CXQ - 0,620 (0,606 adj. }) \text { - moderate-substantial } \\
\text { LOYL - 0,469 (0,462 adj. }) \text { - moderate } \\
\text { PWOM - 0,449 (0,442 adj. }) \text { - moderate }\end{array}$ \\
\hline $\begin{array}{l}\text { Predictive relevance } \\
\text { (in-sample predictive } \\
\text { power) }\end{array}$ & $\mathrm{Q}^{2}$ value & $\begin{array}{l}>0 \\
(0 ; 0,25 ; 0,5)\end{array}$ & $\begin{array}{l}\text { CSAT }-0,265-\text { medium } \\
\text { CXQ }-0,542 \text { - large } \\
\text { LOYL }-0,236-\text { small-medium } \\
\text { PWOM }-0,276 \text { - medium }\end{array}$ \\
\hline \multirow[t]{2}{*}{$\begin{array}{l}\text { PLSpredict (out-of- } \\
\text { sample predictive } \\
\text { power) }\end{array}$} & $\mathrm{Q}^{2}$ predict & $>0$ & $\begin{array}{l}\text { CSAT }-0,237 \\
\text { CXQ }-0,603 \\
\text { LOYL }-0,158 \\
\text { PWOM }-0,083\end{array}$ \\
\hline & RMSE/MAE & PLS $<$ LM & $\begin{array}{l}\text { A minority of indicators yields higher prediction } \\
\text { errors in PLS compared to LM benchmark - } \\
\text { medium predictive power. }\end{array}$ \\
\hline \multirow{2}{*}{$\begin{array}{l}\text { Significance and } \\
\text { relevance of path } \\
\text { coefficients }\end{array}$} & P-value & $<0,05$ & P-values less than $<0,05$ and confidence interval \\
\hline & \begin{tabular}{|l}
$95 \%$ \\
confidence \\
interval
\end{tabular} & not include 0 & $\begin{array}{l}\text { does not include } 0 \text { for NFL, ERM, CSAT, CXQ, } \\
\text { but p-value of HPE }(0,303) \text { is above } 0,05 \text { and } \\
\text { confidence interval includes } 0 .\end{array}$ \\
\hline $\begin{array}{l}\text { Relevance of path } \\
\text { coefficients }\end{array}$ & $\begin{array}{l}\text { Path } \\
\text { coefficient }\end{array}$ & $\geq 0,5$ & $\begin{array}{l}\mathrm{NFL} \rightarrow \mathrm{CXQ}-0,453-\text { medium } \\
\mathrm{ERM} \rightarrow \mathrm{CXQ}-0,352-\text { weak-medium } \\
\mathrm{HPE} \rightarrow \mathrm{CXQ}-0,060-\text { weak } \\
\mathrm{CXQ} \rightarrow \mathrm{CSAT}-0,578-\text { medium } \\
\mathrm{CSAT} \rightarrow \mathrm{LOYL}-0,685-\text { medium-strong } \\
\mathrm{CSAT} \rightarrow \mathrm{PWOM}-0,670 \text { - medium-strong }\end{array}$ \\
\hline
\end{tabular}

Notes: Bootstrapping based on 5000 subsamples; PLS Predict based on 10 folds and 10 repetitions 
Table 4. Effects of endogenous variables

\begin{tabular}{|c|c|c|c|c|c|c|c|}
\hline & $\mathrm{R}^{2}$ & $\mathrm{Q}^{2}$ & Direct effect & t-value & $\begin{array}{l}\text { Percentile bootstrap } \\
90 \% \text { CI }\end{array}$ & Significance & $\mathrm{f}^{2}$ \\
\hline$C X Q$ & 0,620 & 0,542 & & & & & \\
\hline NFL (H1) & & & 0,453 & 3,848 & {$[0,289 ; 0,681]$} & Significant & 0,182 \\
\hline ERM (H2) & & & 0,352 & 3,939 & {$[0,191 ; 0,486]$} & Significant & 0,164 \\
\hline HPE (H3) & & & 0,060 & 0,526 & {$[-0,178 ; 0,201]$} & Non-significant & 0,003 \\
\hline CSAT & 0,334 & 0,265 & & & & & \\
\hline CXQ (H4) & & & 0,578 & 3,338 & {$[0,232 ; 0,807]$} & Significant & 0,502 \\
\hline$L O Y L$ & 0,469 & 0,236 & & & & & \\
\hline CSAT (H5) & & & 0,685 & 9,179 & {$[0,520 ; 0,775]$} & Significant & 0,882 \\
\hline$P W O M$ & 0,449 & 0,276 & & & & & \\
\hline CSAT (H6) & & & 0,670 & 6,633 & {$[0,457 ; 0,793]$} & Significant & 0,814 \\
\hline
\end{tabular}

Notes: Bootstrapping based on $\mathrm{n}=5000$ subsamples

\subsection{Discussion of the results}

Results of the structural model analysis point out to the predominant medium positive effect $(0,453)$ of the recollected needs fulfillment level, weak-medium positive effect $(0,352)$ of the recollected efficient resource management, and weak positive effect $(0,060)$ of the recollected human perception engagement on the recollected customer experience quality. Medium positive effect $(0,578)$ of the recollected customer experience quality on the customer satisfaction and medium-high positive effect of the customer satisfaction on customer loyalty $(0,685)$ and positive word-of-mouth $(0,670)$ is in line with previous findings [e.g. 3, 19].

The analysis of the reflective measurement model of the needs fulfillment level consisting of the fulfillment of the human basic needs, social needs, growth needs, customer's utilitarian needs, and hedonic needs indicate the highest loading for the fulfillment of the social needs $(0,912)$, then utilitarian needs $(0,845)$, basic needs $(0,815)$, hedonic needs $(0,674)$ and the lowest for the growth needs $(0,562)$. In terms of the formative measurement model for the efficient resource management, efficient time management has the highest importance $(0,628)$, efficient money management has the lower importance $(0,433)$, and efficient energy management has by far the lowest importance $(0,017)$. In the case of the human perception engagement, the affective dimension has the highest importance $(0,671)$, followed by the sensory dimension $(0,407)$, cognitive dimension $(-0,217)$, and behavioral dimension $(0,212)$.

A possible explanation for the results can be found, for example through the statement of Kahneman [21] points to the fact, that present is fleeting and people have only memories and evaluations of the past. In this context, basically, humans are equipped with the long-term memory, where general knowledge (semantic memory) and spatio-temporal events (episodic memory) can be stored [21, 22] as well as emotion-related links [23]. Based on the importance of the present stimuli, the experience remains encoded in the memory for a corresponding time and with corresponding information quality. [24] Therefore respondents of the questionnaire rely on the memory of different quality of their experiences and its retrieval/reconstruction (it should be noted, that in both cases there is a significant risk of bias and error when the respondent „thinks“ more or less or different about the past experience than he would in real-life situations or when there is no stored information, related to the question, accessible to the consciousness).

It is then possible to assume, that it is much easier for customers (in terms of the effort, not accuracy) to evaluate/report on affective engagement, as emotions are an important part of the remembering and memory, or sensory engagement based on reconstructed imagery 
from spatio-temporal memory than cognitive engagement or even behavioral engagement that requires more effortful retrospection or existence of the experience related facts (the same applies for the growth needs fulfillment). Similarly, it could be concluded that it is much easier (again, in terms of the effort not accuracy) to evaluate/report on financial efficiency (single fact), or time efficiency (based on spatio-temporal memory), than to evaluate energy efficiency. Difficult questions (concepts) or questions related to the nonexisting memory content might then stimulate neutral answers or careless responding.

\section{Conclusions}

The recent marketing phenomenon of customer experience is in the academic and managerial focus for more than two decades. Despite that, researchers and managers dealing with the concept of experience are still struggling to define and conceptually holistically describe the whole concept, as it spreads across disciplines. This research builds upon one possible way to holistically perceive customer experience through customer's needs fulfillment level, efficient resource management and human perception engagement, factors proposed by the author and uses it as the foundation for the analysis of antecedents and marketing consequences of the memorized customer experience quality in the area of sharing economy services.

\subsection{Findings}

The analysis of the data supported the five out of the six hypotheses related to the recollected customer experience quality antecedents, its recent recollection, and marketing consequences in the sharing economy environment. This research points out the medium positive effect $(0,453)$ of the needs fulfillment level on the overall recollected customer experience quality with the sharing economy companies. The second factor, resource management efficiency, has medium to weak positive effect $(0,352)$ on the overall recollected customer experience quality. The third factor, human perception engagement has a weak effect $(0,06)$ on the overall recollected customer experience quality. All three factors then explain approximately $62 \%$ of the recollected customer experience quality variance. Recollected customer experience quality has a medium positive effect $(0,578)$ on customer satisfaction and explains approximately $33 \%$ of its variance. Further, customer satisfaction has a strong to a medium positive effect on both customer loyalty $(0,685)$ and customer's positive word-of-mouth $(0,670)$ and explains approximately $47 \%$ of customer loyalty variance and $45 \%$ of positive word-of-mouth variance.

It could be concluded that in the context of sharing economy experience the most influential on the recollected customer experience quality are the fulfillment of the lowerorder/deficiency needs (particularly social/belonging), then hedonic and growth needs, solution of the customer's intended goals, and efficient use of his time and money. [25]

\subsection{Limitations and future research}

The key methodological limitation of this pilot research is the sample size in terms of the number of the respondents and its diversity, further research therefore could address that by collecting the data from more respondents across different age groups, cultural backgrounds, etc., as well as in a context of wider variety of companies. Another methodological limitation is the use of the not yet validated conceptual model and measurement scales, therefore further research should be focused on the testing and validation of the model as well as the measurement scales with the possible inclusion of the validated measurement scales for the 
relevant concepts, and addition of the items for the identification of careless responses and the assessment of convergent validity.

Future research in the field of the customer experience could also be phenomenologically oriented and focused on the further development of the holistic non-reductionist conceptual model of the customer experience based on the multidisciplinary knowledge that would address the issue of the difference between predicting, living, thinking about living and remembering. From this perspective comparison between evaluations of the customer experience during the experience and in specific times after the experience could be the next possible avenue for future research.

This research is a part of a project Comparison of the marketing approaches in the areas of B2B and B2C led by Ing. Jan Machala (FP-J-20-6415).

\section{References}

1. De Keyser, A., Verleye, K., Lemon, K.N., Keiningham, T.L., Klaus, P. (2020). Moving the Customer Experience Field Forward: Introducing the Touchpoints, Context, Qualities (TCQ) Nomenclature. Journal of Service Research, 94(9), 1-23.

2. Becker, L., Jaakkola, E. (2020). Customer experience: fundamental premises and implications for research. Journal of the Academy of Marketing Science, 48, 630-648.

3. Klaus, P., Maklan, S. (2013). Towards a better measure of customer experience. International Journal of Market Research, 55(2), 227-21.

4. Schmitt, B. (1999). Experiential Marketing. Journal of Marketing Management, 15(13), 53-67.

5. Havir, D. (2019). Towards fully-fledged conceptualization of customer experience. In Z. Bučková, L. Rusňáková, M. Solík (Eds.). Megatrends and Media: Proceedings of the International Scientific Conference Megatrends and Media: Digital Universe (pp. 508530). Trnava: Faculty of Mass Media Communication, University of SS. Cyril and Methodius in Trnava.

6. Mehrabian, A., Russell, J.A. (1974). An approach to environmental psychology. Cambridge: MIT Press.

7. Holbrook, M.B. (1986). Emotions in the consumption experience: toward a new model of consumer behavior. In Peterson, R. A., Hoyer, W.D. and Wilson, W.R. (Eds), The Role of Affect in Consumer Behavior: Emerging Theories and Applications (pp. 17-52). Lexington: Heath.

8. Gutman, J. (1982). A Means-End Chain Model Based on Consumer Categorization Processes. Journal of Marketing, 46(2), 60-72.

9. Havir, D. (2020). Customer Experience: Taking step back towards the next level. Manuscript submitted for publication. Department of Management, Faculty of Business and Management, Brno University of Technology.

10. European Commission (2016). A European agenda for the collaborative economy. European Commission. Retrieved from: https://ec.europa.eu/growth/toolsdatabases/vto/policy/european-agenda-collaborative-economy

11. Schlagwein, D., Schoder, D., Spindeldreher, K. (2019). Consolidated, systemic conceptualization, and definition of the "sharing economy." Journal of the Association for Information Science and Technology, 71(7), 817-838.

12. Martin, C.J. (2016). The sharing economy: A pathway to sustainability or a nightmarish form of neoliberal capitalism? Ecological Economics, 121, 149-159. 
13. European Commission (2018). The use of the collaborative economy. European Commission. Retrieved from: https://ec.europa.eu/commfrontoffice/publicopinion/index.cfm/Survey/getSurveyDetail /instruments/FLASH/search/collaborative/surveyKy/2184

14. Hair, J.F., Hult, G.T.M., Ringle, C.M., Sarstedt, M. (2017). A Primer on Partial Least Squares Structural Equation Modeling (PLS-SEM). Thousand Oaks: Sage.

15. Hair, J.F., Risher, J.J., Sarstedt, M., Ringle, C.M. (2019). When to use and how to report the results of PLS-SEM. European Business Review, 31(1), 2-24.

16. Sarstedt, M., Hair, J.F., Cheah, J.-H., Becker, J.-M., Ringle, C.M. (2019). How to specify, estimate, and validate higher-order constructs in PLS-SEM. Australasian Marketing Journal, 27(3), 197-211.

17. Denning, S. (2014). An economy of access is opening for business: five strategies for success. Strategy \& Leadership, 42(4), 14-21.

18. Sarstedt, M., Mooi, E. (2018). A Concise Guide to Market Research. Berlin: Springer.

19. Roy, S. (2018). Effects of customer experience across service types, customer types and time. Journal of Services Marketing, 32(4), 400-413.

20. Kahneman, D. (1999). Objective Happiness. In D. Kahneman, E. Diener, N. Schwarz (Eds.), Well-Being (pp. 3-25). New York: Russell Sage Foundation.

21. Roediger III, H.L., Zaromb, F.M., Lin, W. (2017) A Typology of Memory Terms. In: Menzel, R. (ed.), Learning Theory and Behavior, Vol. 1 of Learning and Memory: A Comprehensive Reference, 2nd edition, Byrne, J.H. (ed.). pp. 7-19. Oxford: Academic Press.

22. Weidemann, C.T., Kragel, J.E., Lega, B.C., Worrell, G.A., Sperling, M.R., Sharan, A.D., et al. (2019). Neural activity reveals interactions between episodic and semantic memory systems during retrieval. Journal of Experimental Psychology: General, 148(1), 1-12.

23. Levine, L.J., Lench, H.C., Safer, M.A. (2009). Functions of remembering and misremembering emotion. Applied Cognitive Psychology, 23(8), 1059-1075.

24. Kaplan, R.L., Van Damme, I., Levine, L.J. (2012). Motivation Matters: Differing Effects of Pre-Goal and Post-Goal Emotions on Attention and Memory. Frontiers in Psychology, 3, 1-9.

25. Csikszentmihalyi, M. (2000). The Costs and Benefits of Consuming. Journal of Consumer Research, 27(2), 267-272. 